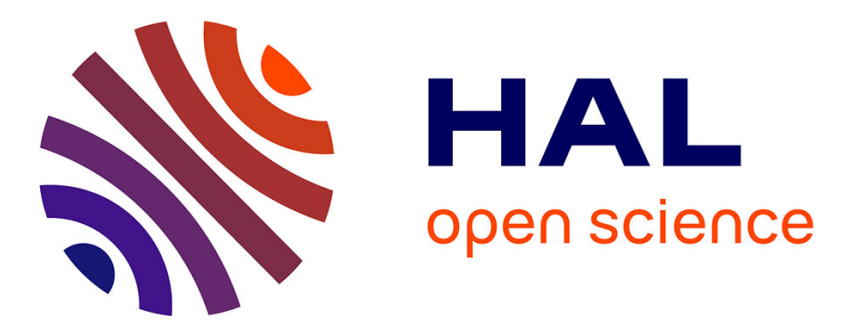

\title{
A numerical study of the formation of the Rhone river plume
}

Patrick Marsaleix, Claude Estournel, Véronique Kondrachoff, Raoul Véhil

\section{To cite this version:}

Patrick Marsaleix, Claude Estournel, Véronique Kondrachoff, Raoul Véhil. A numerical study of the formation of the Rhone river plume. Journal of Marine Systems, 1998, 14 (2), pp.99-115. 10.1016/S0924-7963(97)00011-0 . hal-00160812

\section{HAL Id: hal-00160812 \\ https://hal.science/hal-00160812}

Submitted on 26 Oct 2021

HAL is a multi-disciplinary open access archive for the deposit and dissemination of scientific research documents, whether they are published or not. The documents may come from teaching and research institutions in France or abroad, or from public or private research centers.
L'archive ouverte pluridisciplinaire HAL, est destinée au dépôt et à la diffusion de documents scientifiques de niveau recherche, publiés ou non, émanant des établissements d'enseignement et de recherche français ou étrangers, des laboratoires publics ou privés.

\section{(c)(1)}

Distributed under a Creative Commons Attribution| 4.0 International License 


\title{
A numerical study of the formation of the Rhône River plume
}

\author{
Patrick Marsaleix ${ }^{*}$, Claude Estournel, Veronique Kondrachoff, Raoul Vehil \\ Laboratoire d'Aérologie UMR CNRS / UPS 5560, 14 Avenue Edouard Belin, 31400 T'oulouse, France
}

A three-dimensional primitive equation ocean model is applied to the Rhône River plume (northwestern Mediterranean). The plume dynamics are analyzed through the vorticity balance of the depth-averaged current. This balance highlights the importance of the JEBAR and nonlinear terms. The topography induces the freshwaters to enter the Gulf of Fos and progress eastwards. The momentum advection is responsible for the large offshore extension of the plume. Northwestern winds (characteristic of the regional climate) may detach the plume from the coast. The wind stress magnitude required for this detachment is commensurate with Garvine's dimensional analysis. A satisfactory comparison is made between the numerical experiments and satellite observations for weak and strong wind conditions. Finally, a sensitivity test of the model to the vertical coordinate reveals that a double-sigma system preserves the salinity gradients and current intensity in the frontal zones of the plume better than a conventional sigma coordinate.

Keywords: river plume; Northwestern Mediterranean; the Rhône; JEBAR effect; twofold sigma coordinate

\section{Introduction}

The main characteristics of estuarine plumes are known, for the most part, through satellite imagery and modeling studies (Chao and Boicourt, 1986; O’Donnell, 1990; Kourafalou et al., 1996a,b). Globally, after leaving the river mouth, the light waters enter an anticyclonic eddy which the coastal current extends. The three-dimensional structure of the currents as revealed by the models involves a cyclonic undercurrent beneath the anticyclonic bulge. Numerical studies have demonstrated the sensitivity of these characteristics to certain parameters: the two-layer flow inside the estuary constitutes a source for the

\footnotetext{
* Corresponding author. Fax: +33 6133-2790; e-mail: marp@aero.obs-mip.fr
}

surface circulation and a sink deeper down for the plume entering the adjacent sea. In nearly inviscid models, the Froude number determines the shape of the plume, and varies depending on whether the plume is supercritical or subcritical (Garvine, 1987; Chao, 1988): a supercritical plume is characterized by a bulge with a considerable seaward extension, followed by a narrow coastal current, while a subcritical plume is characterized by a bulge whose width is comparable to that of the coastal current. The width of the coastal current is comparable to that of the Rossby radius (Stern et al., 1982) in the inviscid case but may be significantly larger in the case of diffusive plumes. In many cases, river plume dynamics may differ from the 'anticyclonic eddy-coastal current' system described by Chao and Boicourt (1986). Indeed, the determining factor in the plume shape can be an alongshore current (Garvine, 1987), 
tidal currents or the wind (Lentz and Limeburner, 1995; Kourafalou et al., 1996a). The topography of the continental shelf also plays an important role since the effect of a seaward bottom slope is to limit the offshore development of the bulge by increasing the anticyclonic vorticity linked to the orographic lifting of the undercurrent (Chao, 1988), while the presence of a canyon in front of the mouth reinforces the barotropic circulation with the emission of coastally trapped waves (Weaver and Hsieh, 1987).

In this study, we examine the plume of the Rhône, which is one of the largest discharges of freshwater into the western Mediterranean. Its mean discharge is about $2000 \mathrm{~m}^{3} / \mathrm{s}$, but frequent autumn and spring floods lead to discharges exceeding $5000 \mathrm{~m}^{3} / \mathrm{s}$. These floods are of prime importance, since they transport to the sea considerable quantities of continental matter, whose fate needs to be studied. The three-dimensional circulation caused by the buoyancy flux, characterizing the arrival of freshwaters into the sea, plays a role which is not yet fully understood. From a more fundamental point of view, the aforementioned parameters which govern plume circulation are significantly different in the case of the Rhône than the ones used in the numerical studies mentioned above. For example, the width of the Rhône at its mouth ( $1 \mathrm{~km})$, small in comparison with the deformation radius, and its shallow depth (2 $\mathrm{m}$ ), do not generally enable the development of three-dimensional estuarine circulation. The speeds at the river mouth are high, greater than $2 \mathrm{~m} / \mathrm{s}$ for a discharge of $5000 \mathrm{~m}^{3} / \mathrm{s}$, and entail significant advective effects, as will be discussed below.

Our study of the Rhône River plume dynamics is conducted through three-dimensional numerical modeling. A two-fold sigma coordinate model is used, making it possible, on the one hand, to preserve a fine vertical resolution in the surface freshwater layer despite the seaward bottom slope and, on the other hand, to accurately represent the effects of the topography on the circulation under the plume. The simulations performed in the absence of wind are analyzed by means of the depth-averaged current vorticity equation. This approach makes it possible to quantitatively take into account the set of processes acting on the plume, including both intrinsic processes related to the density gradients and external forcings caused by the topography. We will also examine the effect of offshore winds, dominant in this region, on the detachment of the plume from the coast. Satellite images of surface temperature illustrate the situations studied, thus making it possible to assess the validity of the model results.

\section{Presentation of the model}

\subsection{Equations}

The model used is an adaptation of the one described by Pinazo et al. (1996). The governing equations were obtained by assuming that mass, momentum and salinity are conserved, and then applying the Boussinesq approximation and hydrostatic equilibrium. Within a rectangular Cartesian coordinate system, $O x_{1} x_{2} x_{3}$ in which the origin, $O$, corresponds to the equilibrium level of the sea surface and $O x_{3}$ is directed upwards along the local vertical, the Reynolds-averaged components of the velocity, $\left(u_{1}, u_{2}, u_{3}\right)$, satisfy:

$$
\begin{aligned}
& \frac{\partial u_{j}}{\partial x_{j}}=0 \\
& \frac{\partial u_{i}}{\partial t}+\frac{\partial u_{j} u_{i}}{\partial x_{j}}-\varepsilon_{i, j, 3} f u_{j} \\
& =-\frac{g}{\rho_{0}} \frac{\partial}{\partial x_{i}} \int_{x_{3}}^{\eta} \rho \mathrm{d} x_{3}+\frac{\partial}{\partial x_{3}}\left(K \frac{\partial u_{i}}{\partial x_{3}}\right)+A \Delta_{h} u_{i}
\end{aligned}
$$$$
\text { for } i=1,2
$$

where $f$ denotes the Coriolis parameter, $\varepsilon$ the alternating unit tensor, $\eta$ the position of the sea surface, $\rho_{0}$ a reference density, $\Delta_{h}=\left(\partial^{2} / \partial x_{1}^{2}\right)+\left(\partial^{2} / \partial x_{2}^{2}\right)$, and $A$ the horizontal diffusivity, taken to be 10 $\mathrm{m}^{2} / \mathrm{s}$. The displacement of the sea surface is deduced from a vertically integrated form of the equation of continuity (Eq. (1)), in which:

$$
\frac{\partial \eta}{\partial t}+\frac{\partial}{\partial x_{j=1,2}}\left(H \overline{u_{j}}\right)=0
$$

where $H$ denotes the total depth, and the overbar the average over depth. The density, $\rho$, is derived from the water salinity, $S$, using the following linearized equation of state:

$\rho=\rho_{0}\left[1+\beta\left(S-S_{0}\right)\right]$ 
where the saline contraction, $\beta$, is taken to be 7.45 $\times 10^{-4} \mathrm{psu}^{-1}$, and $S_{0}$ is the reference salinity corresponding to $\rho_{0}$. For the sake of simplicity, we have omitted the effect of the temperature on the water density. The temperature of the Rhône River water at the mouth may fall below $8^{\circ} \mathrm{C}$ in the winter and can attain $22^{\circ} \mathrm{C}$ in the summer (CTGREF, 1977), while the monthly average of sea surface temperature in the Gulf of Lions generally ranges from $13^{\circ} \mathrm{C}$ to $22^{\circ} \mathrm{C}$. We thus felt that temperature differences between the Rhône River and the ambient seawater may generally be considered small enough to assume in the remainder of this article that the buoyancy effects in the plume are represented by salinity gradients only.

The salinity is determined from:

$$
\frac{\partial S}{\partial t}+\frac{\partial u_{j} S}{\partial x_{j}}=\frac{\partial}{\partial x_{3}}\left(K \frac{\partial S}{\partial x_{3}}\right)+A \Delta_{h} S
$$

The transfer coefficient $K$ is defined in terms of the turbulence energy density, $E$, using the following relation:

$$
K=c_{k} l_{k} E^{1 / 2}
$$

$E$ is determined from:

$$
\begin{aligned}
\frac{\partial E}{\partial T}+\frac{\partial u_{j} E}{\partial x_{j}}= & K\left[\left(\frac{\partial u_{1}}{\partial x_{3}}\right)^{2}+\left(\frac{\partial u_{2}}{\partial x_{3}}\right)^{2}\right] \\
& +\frac{g}{\rho_{0}} K \frac{\partial \rho}{\partial x_{3}}+\frac{\partial}{\partial x_{3}}\left(K \frac{\partial E}{\partial x_{3}}\right)-\varepsilon_{d}
\end{aligned}
$$

The rate of loss of the turbulence energy, $\varepsilon_{d}$, is represented by:

$\varepsilon_{d}=\frac{c_{\varepsilon} E^{3 / 2}}{l_{\varepsilon}}$

Following Gaspar et al. (1990), the turbulent scales $l_{\varepsilon}$ and $l_{k}$ are given by:

$l_{k}=\min \left(l_{u}, l_{d}\right)$

$l_{\varepsilon}=\sqrt{l_{u} l_{d}}$

$\frac{g}{\rho_{0}} \int_{x_{3}}^{x_{3}+l_{u}}\left(\rho\left(x_{3}\right)-\rho\left(x_{3}^{*}\right)\right) \mathrm{d} x_{3}^{*}=E\left(x_{3}\right)$

$\frac{g}{\rho_{0}} \int_{x_{3}}^{x_{3}-l_{d}}\left(\rho\left(x_{3}\right)-\rho\left(x_{3}^{*}\right)\right) \mathrm{d} x_{3}^{*}=E\left(x_{3}\right)$
The empirical constants, $c_{k}$ and $c_{\varepsilon}$, are respectively taken to be 0.1 and 0.7 .

\subsection{Boundary conditions}

The boundary conditions at the free surface and seafloor are:

$\rho_{0} K \frac{\partial u_{i}}{\partial x_{3}}=\left\{\begin{array}{ll}\tau_{\mathrm{s}, i} & \text { at }_{3}=\eta \\ \tau_{\mathrm{b}, i} & \text { atx }_{3}=-h\end{array} \quad i=1,2\right.$

$E= \begin{cases}\frac{\tau_{\mathrm{s}}}{\rho_{0} \sqrt{c_{\varepsilon} c_{k}}} & \text { at } x_{3}=\eta \\ \frac{\tau_{\mathrm{b}}}{\rho_{0} \sqrt{c_{\varepsilon} c_{k}}} & \text { at } x_{3}=-h\end{cases}$

$\rho_{0} K \frac{\partial S}{\partial x_{3}}=0$ at $x_{3}=\eta$ and at $x_{3}=-h$

where $\tau_{\mathrm{s}}$ is the wind stress and $\tau_{\mathrm{b}}$ the bottom stress, calculated as in Blumberg and Mellor (1987).

A no-flux condition is applied across closed lateral boundaries. At the open lateral boundaries, a zero gradient condition is applied to the density field. It should be noted that, because of the initially homogeneous density field, the results described here are not affected by the boundary condition on density since the simulations were ended before the nose of the plume reached the open boundaries. The surface elevation at the lateral open boundary is calculated by the following radiation condition:

$\frac{\partial \eta}{\partial t}+c \frac{\partial \eta}{\partial n}=0$

where $n$ is the coordinate normal to the boundary and $c$ is the wave speed calculated according to Orlanski (1976).

The freshwater discharge of the Rhône into the sea debouches from a channel in which the model equations are reduced to a two-dimensional system $0 x_{1} x_{3}$ which consists simply in eliminating $u_{2}$, the component of the current perpendicular to the river banks, as well as the terms in $\partial / \partial x_{2}$ of Eqs. (1)-(12). The channel is $32 \mathrm{~km}$ long and $2 \mathrm{~m}$ deep. The width of the Rhône River mouth is fixed at $1 \mathrm{~km}$, which closely approximates reality. As the horizontal reso- 


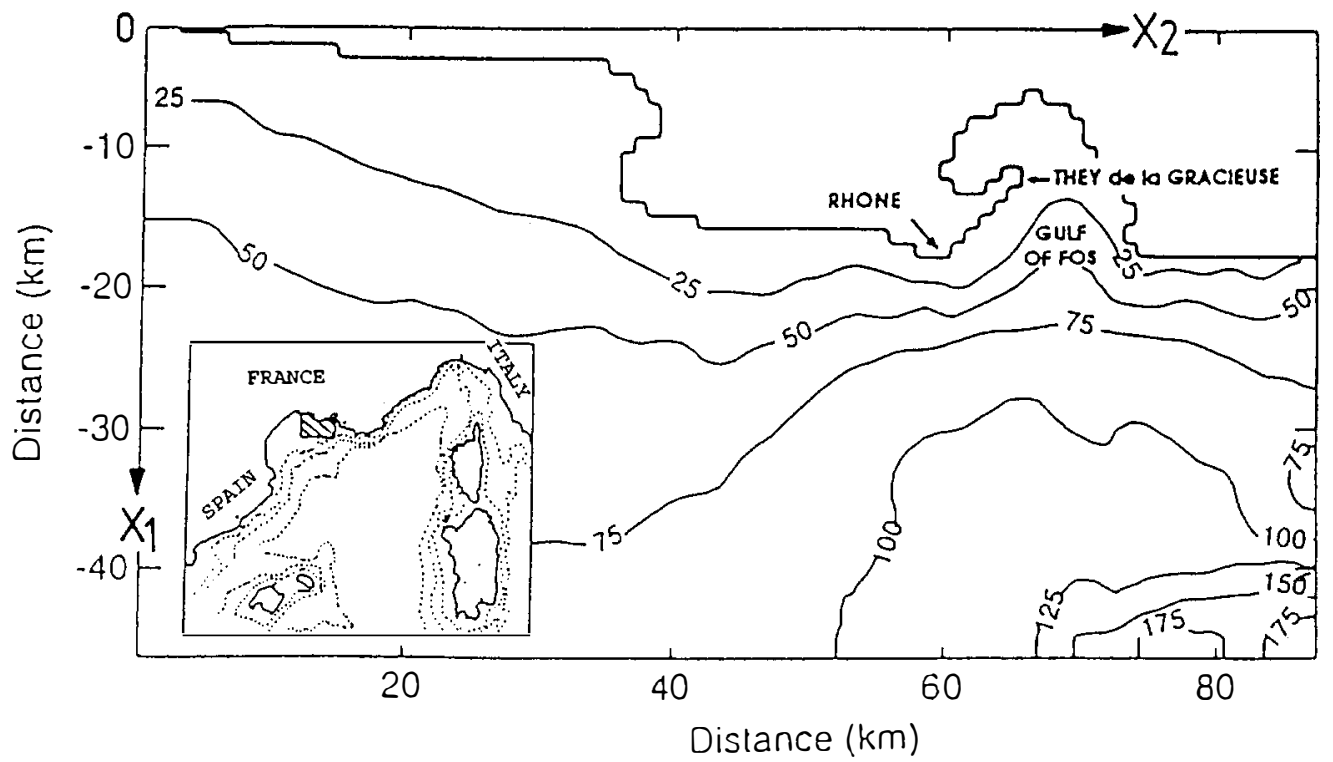

Fig. 1. Coastline and depth contours (in $\mathrm{m}$ ) of the numerical model. Inset: map of the northwestern Mediterranean Sea. The area covered by the model is shaded.

lution of the 3-D ocean model is also $1 \mathrm{~km}$, the coupling with the river model is simply:

$\varphi_{\text {river }}=\varphi_{\text {ocean }}$

where $\varphi$ represents any variable in Eqs. (1)-(12). Boundary conditions at the end of the channel are:

$S=0$

$u_{1}=\frac{F}{l d}$

where $F$ is the river discharge, $l$ the width and $d$ the depth of the channel.

\subsection{The model grid}

The region of the Rhône River plume, the horizontal dimensions of the numerical domain and the bottom topography are shown in Fig. 1. The equations are solved in a three-dimensional 'staggered' C grid (Arakawa and Suarez, 1983). The horizontal resolution is $1 \mathrm{~km} \times 1 \mathrm{~km}$. A leap-frog differencing scheme associated with an Asselin (1972) filter is used for the time-stepping. A mode-splitting technique (Blumberg and Mellor, 1987) is used to calculate the free surface elevation. The vertical grid corresponds to the 'two-fold' sigma coordinate sys- tem described by Deleersnijder and Beckers (1992) consisting in dividing the water column into two regions, each of which is associated with a sigma coordinate. Although it may be stretched by the bottom topography, the thickness of the upper region is restricted to a maximum value of $10 \mathrm{~m}$, which prevents a loss of vertical resolution near the surface in deeper areas. This system is quite suitable for the study of river plumes, especially when wind forcing pushes the thin freshwater layer offshore. Four- and five-sigma levels are, respectively, used for the upper and lower layers.

\subsection{Vorticity equation of the depth-averaged current}

The simulations of the Rhône River plume are analyzed using the equation of depth-averaged current vorticity, $\xi=\varepsilon_{i, j, 3} \partial \overline{u_{j}} / \partial x_{i}$, which may be expressed as:

$$
\begin{aligned}
\frac{\partial \xi}{\partial t}= & -\varepsilon_{i, j, 3} \frac{\partial}{\partial x_{i}}\left[\frac{1}{H} \frac{\partial}{\partial x_{k=1,2}} \int_{-h}^{\eta} u_{k} u_{j} \mathrm{~d} x_{3}\right. \\
& \left.+\frac{g}{\rho_{0} H} \int_{-h}^{\eta} \frac{\partial}{\partial x_{j}}\left(\int_{x_{3}}^{\eta} \rho \mathrm{d} x_{3}^{*}\right) \mathrm{d} x_{3}-\frac{\tau_{\mathrm{s}, j}-\tau_{\mathrm{b}, j}}{\rho_{0} H}\right]
\end{aligned}
$$




$$
\begin{aligned}
& -f \frac{\partial \overline{u_{k}}}{\partial x_{k=1,2}}+\varepsilon_{i, j, 3} \frac{\partial}{\partial x_{i}} \\
& \times\left[\left(\frac{u_{j}}{H} \frac{\partial \eta}{\partial t}\right)+\frac{A}{H} \int_{-h}^{\eta} \Delta_{h} u_{j} \mathrm{~d} x_{3}\right]
\end{aligned}
$$

The term on the left-hand side of Eq. (17) will be referred to below as the change in vorticity over time, while on the right-hand side we find the nonlinear, JEBAR, friction and stretching terms. It should be noted that JEBAR is often expressed (Mertz and Wright, 1992) as:

$$
J\left(\chi, H^{-1}\right)
$$

where

$\chi=\frac{g}{\rho_{0}} \int_{-h}^{\eta} z \rho \mathrm{d} z$

is the potential energy anomaly. The two rightmost terms of Eq. (17), which derive from the variation of the surface level and horizontal-diffusive effects, are negligible when compared to the others, and can thus be legitimately omitted. They are nevertheless calculated in order to attain an exact numerical balance in Eq. (17) (see Appendix A). If the initial state of the simulations is considered to be a zero velocity field, then $\xi(t)$ can be simply calculated by $\xi(t)=$ $\int_{t=0}^{t} \frac{\partial \xi}{\partial t} \mathrm{~d} t$. Therefore, the sum over time of the discrete form of Eq. (17) is chosen as it provides a vorticity balance.

\subsection{Initialization}

The simulations described below are performed using the following assumptions: the freshwater discharge of the Rhône is $5000 \mathrm{~m}^{3} / \mathrm{s}$, typical of the strong floods reported over the past few years, especially in autumn and spring. The initial velocity and salinity fields, which are homogeneous, are respectively taken to be $0 \mathrm{~m} / \mathrm{s}$ and $38 \mathrm{psu}$. The effects of sea temperature on the circulation are not taken into account. No large-scale forcing is applied at the open lateral boundaries, meaning in particular that we have ignored the influence of the large-scale circulation, which can be of the order of 5 to $10 \mathrm{~cm} / \mathrm{s}$ on the continental shelf (Millot, 1990), as well as the tidal currents, which are practically nonexistent in this region (Tsimplis et al., 1995).

\section{Vorticity analysis of the Rhône River plume}

Fig. 2 shows the surface salinity field, surface circulation and bottom circulation after a 48-h simulation without wind forcing. Globally, two main plume-shape characteristics may be discemed, as identified by the numerical studies of Chao and Boicourt (1986). First of all, the plume forms a bulge of anticyclonic circulation in front of the river mouth. The circulation within the bulge is baroclinic and may be considered as a two-layer circulation system in which the direction of the bottom current is opposite to that of the near geostrophic surface flow. Secondly, the anticyclonic surface circulation returns to the coast about $10 \mathrm{~km}$ west of the mouth and then forms a westward coastal current.

According to the classification scheme of Chao (1988), which is based on the offshore extension of the bulge and the width of the coastal current, the computed plume may be considered to be supercritical. Within the inviscid limit, this situation occurs when the internal Froude number, Fr, is greater than one (Chao, 1988). An estimation of this number may be given by $V / c$, where $V$ is the surface velocity in the plume and $c$ the phase speed associated with the first baroclinic mode, obtained by computing the eigenvalues of the normal mode equation on the model grid. We found that the plume was almost entirely characterized by a Froude number greater than 1 and that the baroclinic Rossby radius, $R_{0}=$ $c / f$, was of the order of 3 to $5 \mathrm{~km}$ in the coastal current, whose width is about $10 \mathrm{~km}$. A Kelvin number, $\mathrm{Ke}$, may be obtained from the ratio of the coastal current width to the baroclinic Rossby radius. Within the inviscid limit, Stem et al. (1982) have shown that $\mathrm{Ke}$ is about 0.4 . Here, a value of $\mathrm{Ke}$ greater than 2 indicates the effect of mixing on the plume shape, which may be considered as diffusive, if Chao's classification scheme is once again used. The Kelvin number is the predominant parameter in the classification system of Garvine (1995) for buoyant coastal discharges. We have included here a table (Table 1) from Garvine (1995) which lists values of $\mathrm{Ke}$ and $\mathrm{Fr}$ for various buoyant coastal discharges. 

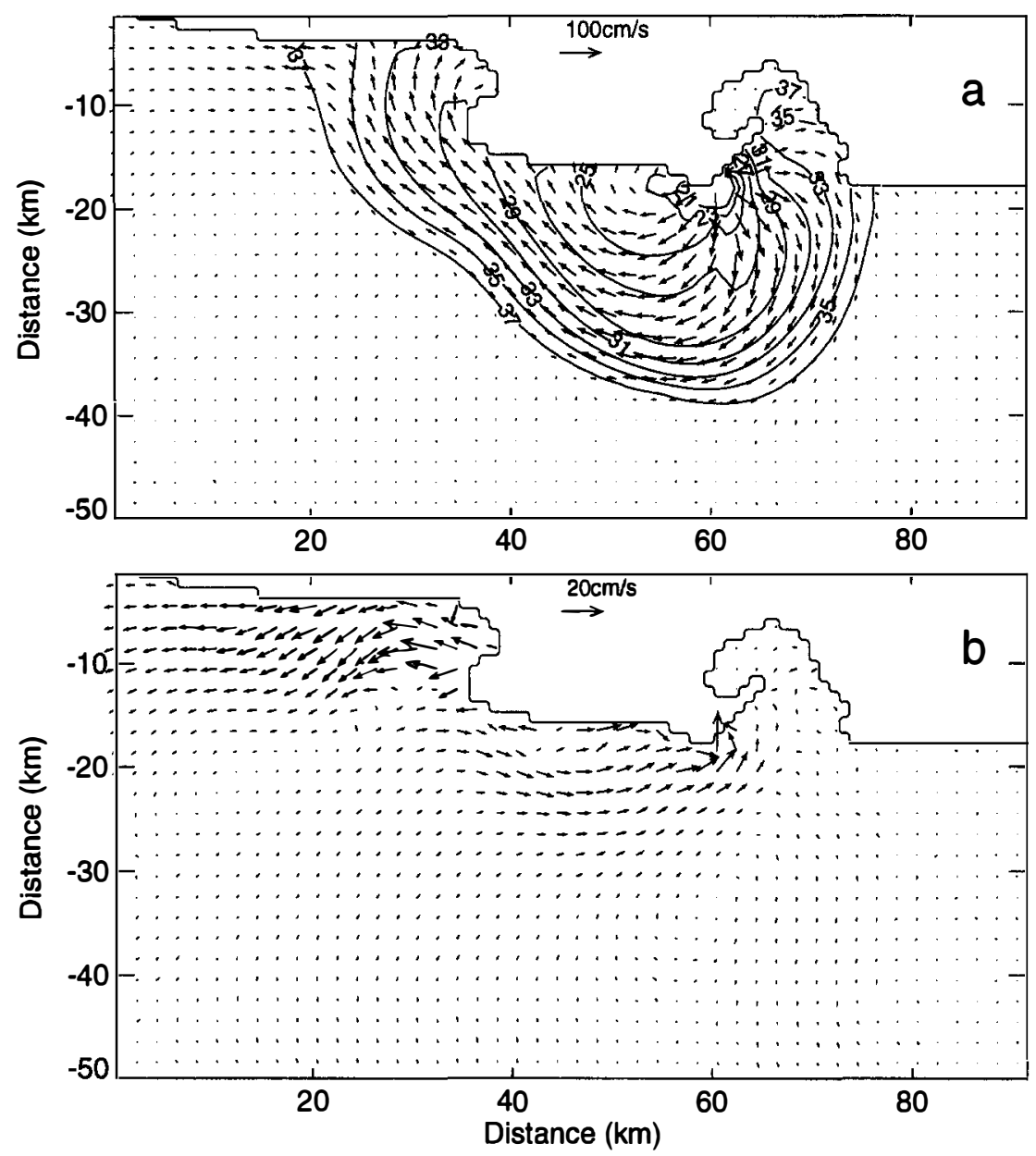

Fig. 2. (a) Computed surface salinity and current, and (b) bottom current after $48 \mathrm{~h}$ of simulation. Interval between salinity isocontours: 2 psu. For the sake of clarity, contours lower than 21 psu and one out of every two vectors in both directions have not been plotted.

One remarkable feature of Garvine's dimensional analysis, as may be seen in Table 1 , is that low Kelvin numbers are normally associated with supercritical plumes and, inversely, high Kelvin numbers with low Froude numbers. It is interesting to note that, according to our numerical experiments, the Rhône River plume does not satisfy this rule, with both $\mathrm{Ke}$ and Fr higher than one. This particular point will be discussed in Section 7.

Chao (1988) showed that the bottom slope restricts the offshore extension of the bulge because of vorticity constraints. Below, the vorticity balance of the depth-averaged current will highlight the influence of the sloping bottom on the plume circulation through the JEBAR terms. A similar approach was employed by Wheless and Klinck (1995), who considered the case of buoyant, neutral and dense plumes. A direct relation may be observed between the structure of the depth-averaged current and the plume shape, as shown in Figs. 2 and 3; indeed, the bulge may be considered as an anticyclonic gyre centered to the southeast of the mouth, and the coastal current as the northem branch of a cyclonic circulation which can be clearly distinguished from the former pattern.

\subsection{In the vicinity of the river mouth}

When the width of an estuary is larger than the baroclinic Rossby radius, a complex three-dimen- 
Table 1

Values of $\mathrm{Ke}$ and Fr for various buoyant coastal discharges (from Garvine, 1995)

\begin{tabular}{lcl}
\hline Name & $\mathrm{Ke}$ & Fr \\
\hline Point Beach & 0.1 & 2.0 \\
Mississippi & 0.2 & 1.0 \\
Amazon & 0.6 & 0.6 \\
Niagara & 1.0 & 1.0 \\
Alaska & 1.0 & 0.3 \\
Gaspé & 2.0 & 0.4 \\
Algerian & 3.0 & 0.3 \\
Rhine & 3.0 & 0.1 \\
Delaware & 4.0 & 0.1 \\
Norwegian & 4.0 & 0.1 \\
Scottish & 10.0 & 0.1 \\
\hline
\end{tabular}

sional circulation may form inside the estuary (Weaver and Hsieh, 1987). This is not the case here since the baroclinic radius calculated by the model is clearly larger than the estuary width $(\sim 1 \mathrm{~km})$. It should be noted that this fact justifies our numerical choice of two-dimensional fluvial circulation. One consequence of this simplification is that the flow is not constrained laterally by advection or the pressure gradient force. When the freshwater discharges into the sea, the flow is suddenly constrained by the baroclinic pressure forces generated by the surrounding seawater. The strong induced bottom current flows in approximately the opposite direction to the surface circulation and converges towards the mouth, mainly from the west and east due to the bathymetri- cal constraints. At the mouth, the adjustment of the sea surface level to the convergence of the bottom current with the river discharge creates a sizable pressure gradient which increases the surface spreading of the plume.

The orographic lifting of the bottom current generates a vertical velocity component of the order of $1.5 \times 10^{-3} \mathrm{~m} \mathrm{~s}^{-1}$. It should be noted that if the realistic bathymetry is replaced with a flat bottom, the simulation yields a stronger undercurrent. Indeed, the bottom slope, due to the vertical movements generated, increases the conversion of kinetic energy, drawn from the bottom circulation, into potential energy.

The freshwater discharges into the sea through the entire water column, and then extends off shore as a bottom-to-surface plume up to a distance of $2 \mathrm{~km}$ from the mouth (Fig. 5a). Beyond this point, the freshwater is diluted with seawater through turbulence and upwelling movements associated with the two-layer circulation. Upwelling movements explain the thinning of the plume, which occurs within a distance comparable to the internal Rossby radius. The thickness of the surface plume which then forms is of the order of $5 \mathrm{~m}$. Mixing with the seawater lessens the plume's vertical stratification. It should, however, be noted that for small discharges, mixing with the seawater occurs in the estuary, and the freshwater thus discharges into the sea as a surface plume.

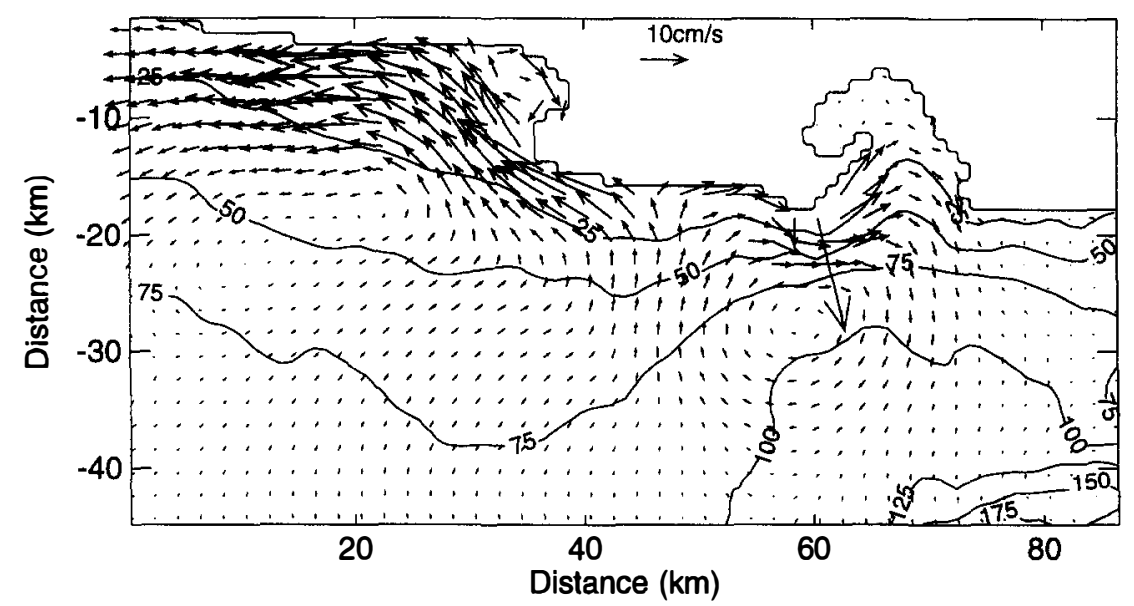

Fig. 3. Depth-averaged current (plotting one out of every two vectors in both directions) after $48 \mathrm{~h}$ of simulation, and depth contours in $\mathrm{m}$. 


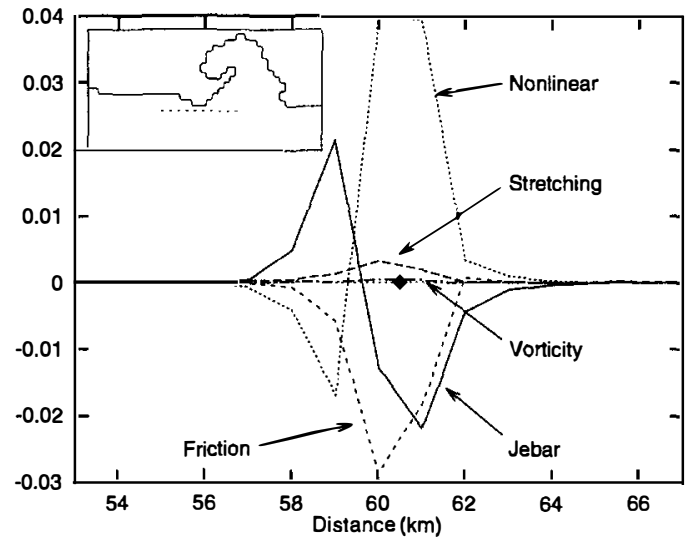

Fig. 4. West-east profile of the time-integrated vorticity components taken $2 \mathrm{~km}$ in front of the river mouth (its location is indicated on the included model map by a dotted line). For the sake of clarity, the change in elevation over time and the horizontal-diffusive terms, which are small in comparison to the others, are not plotted. The black square indicates the position of the river mouth.

A scale analysis reveals that the momentum Eq. (2) is, approximately, a balance between advective, pressure and friction terms within the first few kilometers away from the mouth. Advection is significant because of the strong inflowing current generated by the considerable river discharge and the relatively small mouth of the estuary (roughly 1 $\mathrm{km} \times 2 \mathrm{~m}$ ). Below, we will see that the effect of the advective terms is to lengthen the offshore extension of the plume.

\subsection{Topographical effects in the Gulf of Fos}

One remarkable feature of the plume shape is its eastward extension into the Gulf of Fos, as seen in Figs. 2 and 3. Fig. 4 presents the vorticity balance of the depth-averaged current near the mouth. The net anticyclonic vorticity is associated with the eastward rotation of the depth-averaged current towards the Gulf of Fos. The net vorticity is small when compared to the various terms of the vorticity balance, especially the nonlinear, JEBAR and friction terms. At the mouth $\left(x_{2}=61 \mathrm{~km}\right)$ the nonlinear terms give a cyclonic tendency to the depth-averaged current. Fig. 4 clearly shows the opposition of the JEBAR term to the nonlinear terms. The JEBAR inversion in front of the mouth is to be expected, according to
Wheless and Klinck (1995). Indeed, considering Eq. (18), the combination of the bottom slope, which is approximately aligned in the north-south direction, and the alongshore potential energy gradient, which is clearly negative to the east of the mouth and positive to the west (Fig. 5b), generates an anticyclonic tendency to the east of the mouth (and cyclonic to the west) in opposition to the nonlinear term. It should be noted that in these shallow areas, the vorticity effects of the bottom stress are significant due to the high velocities of the bottom circulation. The bottom friction term has a cyclonic tendency which is globally opposed to the stretching term (Fig. 4).

Farther to the east, the bathymetry of the Gulf of Fos implies that the behavior of the JEBAR term will be opposite to its behavior for the conventional straight coastline and bathymetry case considered by Wheless and Klinck (1995). Indeed, in the latter
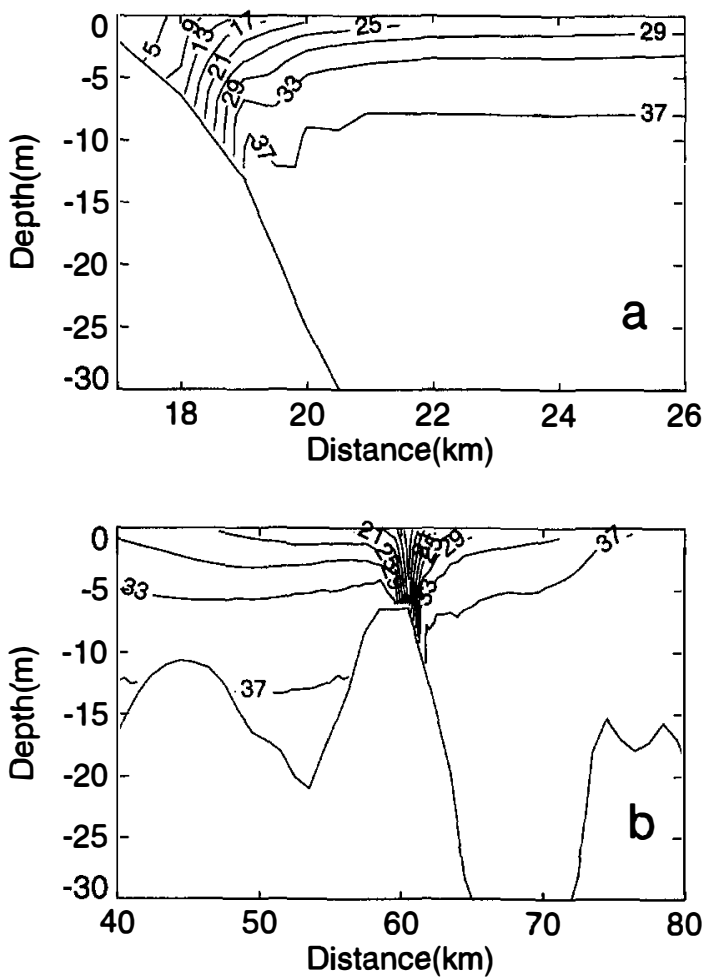

Fig. 5. (a) Vertical north-south section of the salinity taken in front of the river mouth, and (b) vertical west-east section of the salinity taken $2 \mathrm{~km}$ south of the river mouth. The interval between salinity isocontours is 4 psu. 
case, the JEBAR term contributes to the anticyclonic rotation of the circulation to the east of the river mouth. Here, on the other hand, the bottom slope produces a cyclonic JEBAR in the eastem part of the Gulf of Fos, which helps keep the plume flowing alongshore up to Cap Couronne.

\subsection{The anticyclonic bulge}

To the south of the Gulf of Fos, the surface current traces a wide anticyclonic eddy characterized by upwelling movements. As in Chao and Boicourt (1986), the lateral detrainment area found at the fringe of the eddy is characterized by downwelling movements. The vorticity balance of the depth-averaged current (Fig. 6) shows that the bulge is characterized by a net anticyclonic vorticity. At the fringe of the bulge, the lateral detrainment zone displays a net cyclonic vorticity, itself mainly due to the nonlinear terms. The behavior of the JEBAR and stretching terms is as expected: in the easterm half of the bulge, the JEBAR term is negative due to the negative west-east potential energy gradient, and the stretching term is positive due to the thickening of the water column associated with a mean southward current; in the westem half of the bulge, the JEBAR term is positive and the stretching term negative for

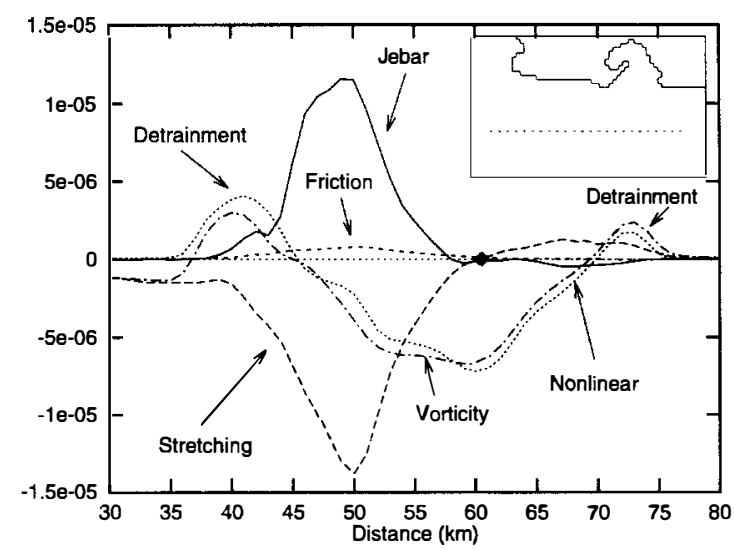

Fig. 6. West-east profile of the time-integrated vorticity components taken $13 \mathrm{~km}$ in front of the river mouth (its location is indicated on the included model map by a dotted line). For the sake of clarity, the change in elevation over time and the horizontal-diffusive terms, which are small in comparison to the others, are not plotted. The black square indicates the position of the river mouth in the west-east direction. Detrainment areas are indicated. the opposite reasons. It may be observed, however, that these terms are more significant in the western half due to the relatively perpendicular orientation of the isobaths with respect to both the pressure contours and to the mean current on the westerm side of the canyon extending in front of the river mouth (Fig. 3). A similar behavior of the JEBAR and stretching terms when confronted with a canyon is seen in Weaver and Hsieh (1987). The effect of the nonlinear term on the depth-averaged current vorticity in the bulge is in the same direction as the resulting vorticity, even within the detrainment areas.

\subsection{The bulge / coastal current transition}

When leaving the bulge, the plume impinges on the coast. Most of the surface plume turns cyclonicly to the west, forming a coastal current, while the remaining part returns to the east, joining in with the anticyclonic circulation of the bulge (Fig. 2a). The bottom circulation consists, first of all, of a counter current detached from the coast and flowing towards the river mouth and, farther downstream, of a current flowing in the same direction as the surface circulation (Fig. 2b). Along the coast, the circulation, when it leaves the bulge, is barotropic as well. This part of the plume is characterized by considerable bottom stress due to the acceleration of the mean current in shoaling areas. This calls to mind the numerical experiments of Chao and Boicourt (1986), showing that the inversion of bottom circulation in the coastal current is sensitive to the bottom friction, with strong friction encouraging barotropic circulation. The convergence of the surface current generates a coastal downwelling with a maximal intensity of $0.3 \mathrm{~m} / \mathrm{h}$. If the vorticity balance is examined, it may be seen that the cyclonic turn of the plume when leaving the bulge is mostly caused by the JEBAR term, while the stretching term contributes, under the effects of the thinning of the water column, to the generation of vorticity, anticyclonic like the sizable friction term in the part of the plume closest to the coast.

\subsection{The coastal current}

During the first few hours of simulation, the plume has not developed long enough to be affected by the rotational effects. It is only when the size of 
the bulge exceeds ten or so kilometers that the anticyclonic circulation appears, with surface currents which are almost parallel to the salinity contours. Ruddick et al. (1994) show that in the case of the Rhine River plume, the distance from the mouth at which the current adjusts itself to a quasi-geostrophic state corresponds to the internal Rossby radius. Here, this distance is greater due to the considerable influence of the advection. The convergence of the anticyclonic current with the coast produces a barotropic coastal circulation. Indeed, a significant $(>1 \mathrm{~cm} / \mathrm{s})$ westward bottom current characterizing the barotropic circulation appears after $9 \mathrm{~h}$ of simulation, $11 \mathrm{~km}$ to the west of the river mouth. After $48 \mathrm{~h}$, it attains about twenty $\mathrm{cm} / \mathrm{s}$ downstream from the salinity front (Fig. 2). Weaver and Hsieh (1987) demonstrated that the presence of a canyon generates, through the JEBAR effect, a stronger barotropic circulation. It is possible that a similar effect is here created by the canyon extending in front of the Rhône River mouth.

\section{Sensitivity of the plume dynamics to the nonlin- ear terms}

The previous simulation demonstrated that the momentum advection is a significant component of the circulation in the plume, not only near the river mouth, due to the high velocities of freshwater discharge, but also throughout the bulge, where it contributes to the vorticity tendency. The shape attained by the plume may thus be considerably different when the advection is omitted. It is in order to demonstrate this point that we now describe a simulation, identical to the previous one, except for the fact that the momentum advection has not been taken into account. Fig. 7 shows the surface and bottom circulation. If it is compared with Fig. 2, the high sensitivity of the plume to the nonlinear terms becomes apparent. At the river mouth, most of the freshwater flows into the Gulf of Fos along the They de la Gracieuse. The mean current is much stronger here, and suggests that the advection terms in the previous simulation drain its energy by lateral mixing. The cyclonic effects of the friction on the bottom of this strong barotropic circulation keep this plume alongside the They de la Gracieuse. The generation of cyclonic vorticity by friction amply compensates for the vorticity generated by the advection, such that the cyclonic turning at the river mouth is stronger than in the simulation without advection. Farther east into the Gulf of Fos, the bottom current weakens, and the frictional effects become negligible while the JEBAR term generates an anticyclonic current rotation. In the simulation with advection, the anticyclonic vorticity generated by the JEBAR term is partially attenuated by the cyclonic tendency of

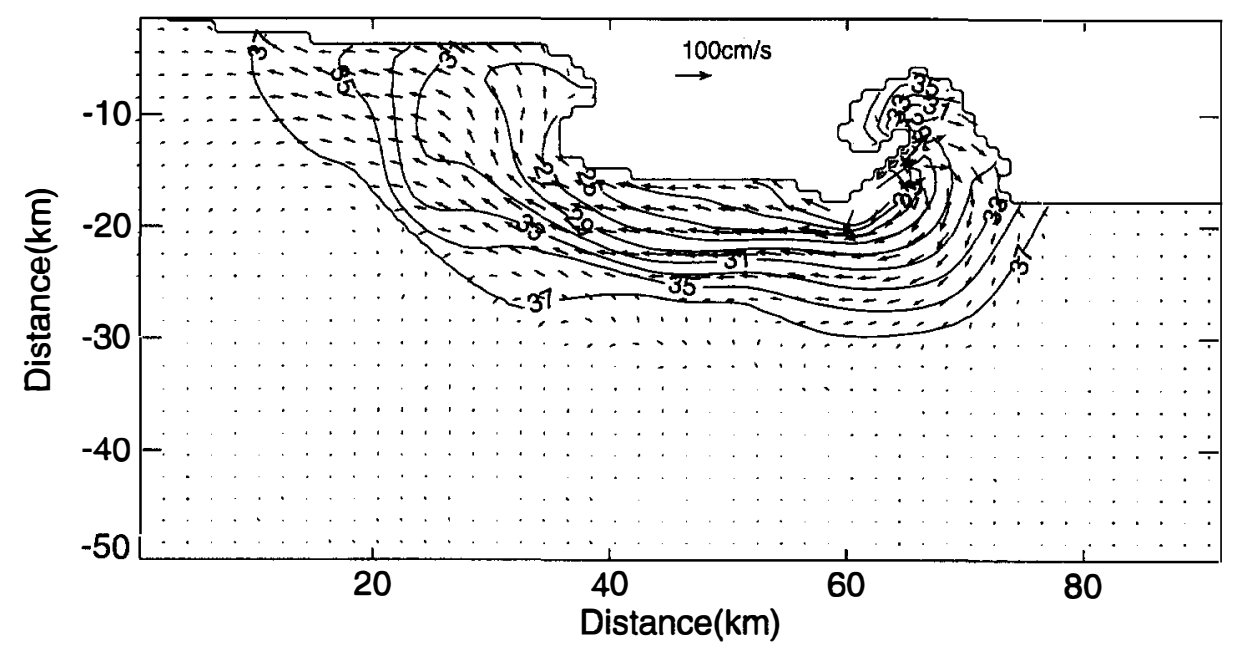

Fig. 7. Computed surface salinity and current after $48 \mathrm{~h}$ of simulation. Interval between salinity isocontours: 2 psu. For the sake of clarity, contours lower than 21 psu and one out of every two vectors in both directions were not plotted. Advective terms in the momentum equations were omitted. 
the nonlinear terms. The absence of advection thus implies a stronger anticyclonic vorticity, resulting in a shorter off shore extension of the bulge. The center of the anticyclonic eddy is now found farther to the east of the river mouth. It is thus possible to observe an eastward off set in the transition between the bulge and the coastal current, which now appears only 4 $\mathrm{km}$ to the west of the river mouth, whereas in the case in which advection was included, this transition occurred $10 \mathrm{~km}$ farther west. It should be noted that these characteristics of the simulation without advection may also be found in simulations with a smaller discharge (not included in this article).

The reduced surface area of the bulge is compensated for by a two-fold thickening of the freshwater layer, resulting from the stronger barotropic circulation to the east of the river mouth, and by the longer westward extension of the plume (Fig. 7). The shape of the coastal current is affected as well: unlike the previous simulation where its width gradually diminished to the west, the nose of the plume is here wider than the coastal current. This effect is somewhat reduced here by the particularities of the coastline and, more specifically, by the Pointe de Beauduc. Indeed, simulations performed with a rectilinear coastline (not included in this article) show that this characteristic is even more pronounced, with currents displaying a fan-shaped nose when the advection is not included. In the absence of advection, the momentum balance in the nose is dominated by the pressure gradient which, due to the unsteadiness of the circulation, widens the intrusion offshore. Farther upstream, the rotation effects are significant and induce a near-geostrophic circulation, involving currents with a shoreward component which tends to make the coastal current narrower behind the nose. The advection effect of the momentum is dominant in the nose because of the small length scale associated with the nose discontinuity and finally pushes the plume back against the coast at the front end of the intrusion.

\section{The influence of the wind}

The local climate of the Gulf of Lions is characterized by strong northwestem winds associated with coastal upwelling (Johns et al., 1992) and internal gravity waves. Demarcq and Wald (1984) demonstrated that northwestem wind conditions may detach the Rhône River plume from the coast. In fact, Garvine (1995) established, through a dimensional analysis of the equations of motion, an order of magnitude for wind stress beyond which the circulation generated by the wind dominates the circulation of the plume itself. This order of magnitude may be expressed by:

$\tau=\frac{\rho H_{\mathrm{p}} c^{2}}{L}$

where $H_{\mathrm{p}}$ and $L$ are respectively the depth and the alongshore length scales of the buoyant structure, and $c$ is the internal phase speed. If, in accordance with Section 3 , we set $c=0.5 \mathrm{~m} \mathrm{~s}^{-1}, H_{\mathrm{p}}=5 \mathrm{~m}$ and $L=40 \mathrm{~km}$, then the plume circulation will be dominated by the wind when the order of magnitude of the wind stress exceeds $3 \times 10^{-2} \mathrm{~N} / \mathrm{m}^{2}$, or, using the parameterization of $\mathrm{Wu}$ (1980), a 10-m wind of the order of $5 \mathrm{~m} / \mathrm{s}$. Plume simulations analogous to the reference simulation but forced by a northwestem wind stress of $0.01 \mathrm{~N} / \mathrm{m}^{2}, 0.035 \mathrm{~N} / \mathrm{m}^{2}, 0.075$ $\mathrm{N} / \mathrm{m}^{2}$ and $0.15 \mathrm{~N} / \mathrm{m}^{2}$, corresponding approximately to winds of $3 \mathrm{~m} / \mathrm{s}, 5 \mathrm{~m} / \mathrm{s}, 7 \mathrm{~m} / \mathrm{s}$ and $10 \mathrm{~m} / \mathrm{s}$, demonstrate the sensitivity of the plume shape to local amospheric forcing and to the coastal circulation generated by the wind. For a wind stronger than $7 \mathrm{~m} / \mathrm{s}$, the plume is clearly deflected seaward (Fig. 8) in accordance with the observations of Demarcq and Wald (1984) and with the order of magnitude given by Eq. (17). Fig. 9a is an observation of the Rhône River plume by AVHRR, when the wind as

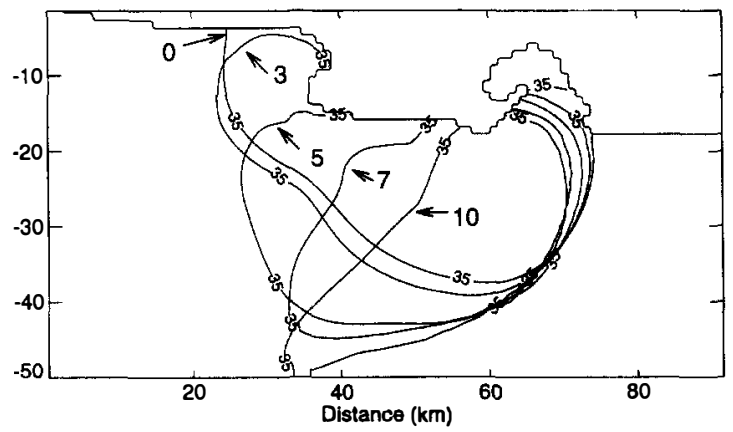

Fig. 8. 35 psu surface salinity isocontours for different values of the northwesterly wind stress, after $48 \mathrm{~h}$ of simulation. The numbers indicate the wind speed (in $\mathrm{m} / \mathrm{s}$ ). 

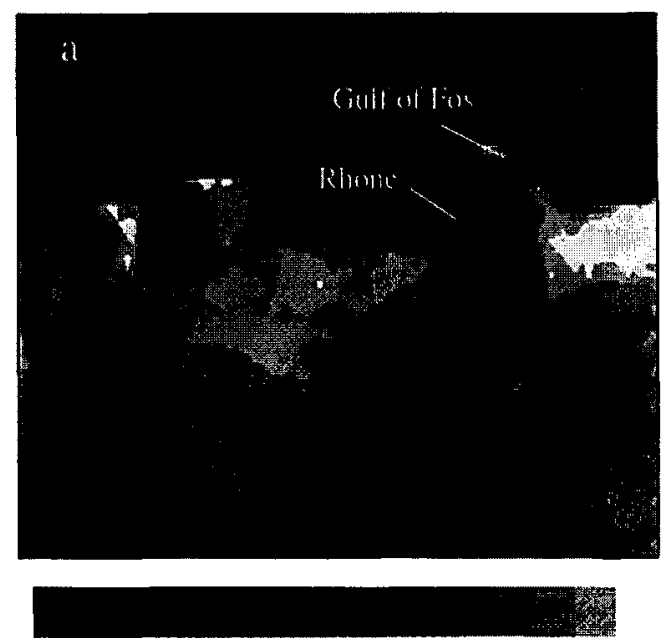

17.5

18.8

20.2
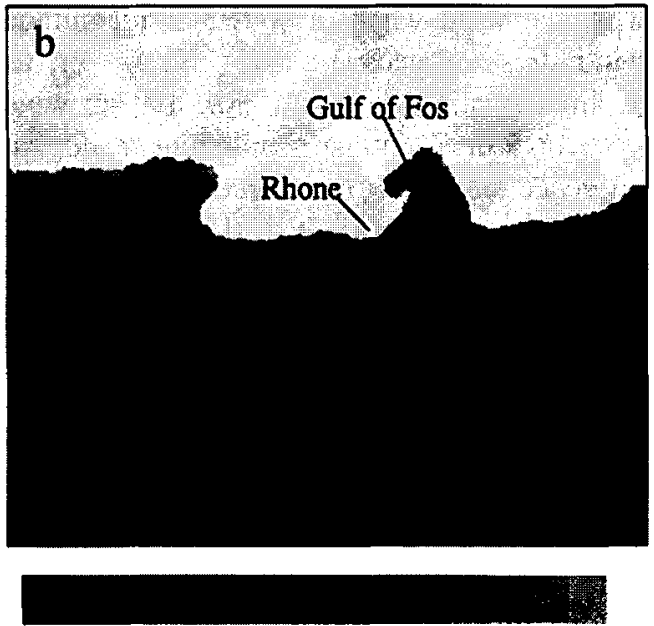

19.0

20.5

22.0

Fig. 9. AVHRR sea surface temperature (in ${ }^{\circ} \mathrm{C}$ ) of the Rhône plume region on (a) 26 September 1993, (b) 7 July 1983.

measured on the island of Pomègues, about $30 \mathrm{~km}$ to the east of the river mouth, was blowing at $12 \mathrm{~m} / \mathrm{s}$ from the northwest, and the Rhône River discharge was about $4000 \mathrm{~m}^{3} / \mathrm{s}$. The plume, darker than the surrounding waters, is clearly separated from the coast, and its overall orientation is towards the southwest in accordance with the plume characteristics as calculated with a wind of $10 \mathrm{~m} / \mathrm{s}$ (Fig. 8). It should be pointed out that the apparent similarity between Figs. 8 and 9 a cannot be considered as a validation of the model, since the initialization and forcing conditions of the simulation took into account neither the variability of the wind and freshwater discharge, nor the oceanic stratification corresponding to the satellite observation. Two salinity fronts may be discemed in the latter plume. The circulation is stronger near the external eastem front than to the west, where the pressure force and wind are in opposition. The circulation generated by the northwestem wind is characterized by the formation of coastal upwelling which increases the rising movements associated with the discharge of freshwater in front of the river mouth. Chao (1988) showed that high-frequency internal gravity waves propagate within the plume. We found that these waves are intensified by the wind and that their direction of propagation corresponds globally to the orientation of the plume (Fig. 10). The southwards orientation of the surrounding surface circulation converges towards the internal westem front of the plume, along which a downwelling develops (Fig. 10). On the opposite side, along the external eastern edge, the downwelling associated with the lateral detrainment is bounded by an upwelling (Fig. 10) resulting from the divergence of the surface current.

For winds weaker than $5 \mathrm{~m} / \mathrm{s}$, the calculated plume clings to the coast and has a form which closely resembles that of the reference circulation without wind. The satellite observation of the plume shown in Fig. $9 \mathrm{~b}$ is characterized by a wind of the order of $3 \mathrm{~m} / \mathrm{s}$ during the $18 \mathrm{~h}$ which precede the image and a Rhône River discharge of $1700 \mathrm{~m}^{3} / \mathrm{s}$, and is thus an example of a plume subjected to a low wind stress, as is attested by its standard form composed of a bulge near the river mouth and the westward alongshore structure. The plume shape, as well as the characteristic size scales of the bulge and coastal current, coincide quite well with those shown in Fig. 8 for the numerical experiment subjected to a wind of $3 \mathrm{~m} / \mathrm{s}$, even though the forceful discharge of $5000 \mathrm{~m}^{3} / \mathrm{s}$ overestimates the reality (a simulation performed with a discharge of $1700 \mathrm{~m}^{3} / \mathrm{s}$ resulted in a similar plume shape). A few characteristics highlighted by the numerical experiment have thus been confirmed by this satellite image, such as, for example, the semi-circular shape of the anticyclonic bulge whose seaward extension is about $18 \mathrm{~km}$, the flow of a fraction of the river water towards the Gulf of Fos along the They de la Gracieuse, and a westward 


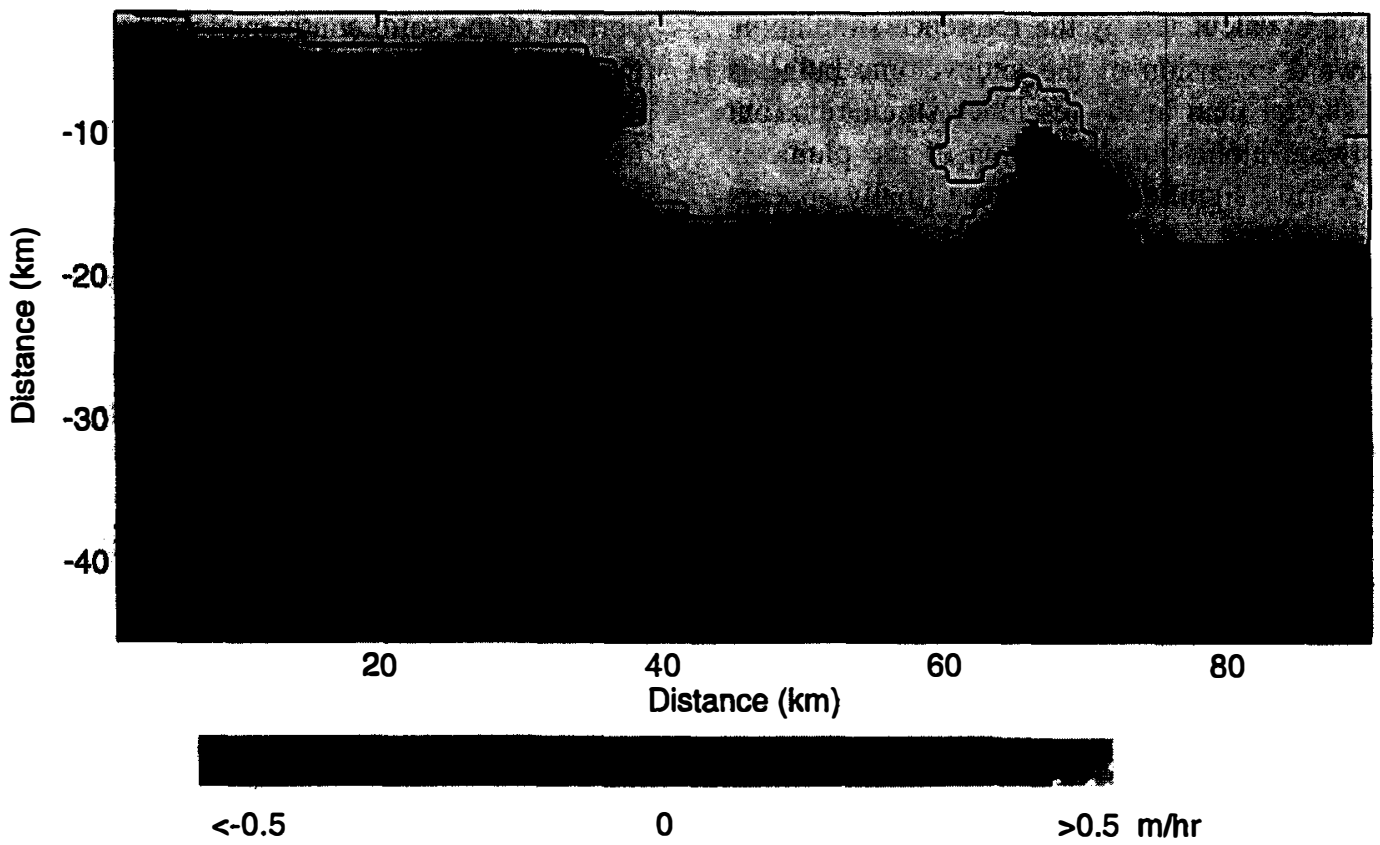

Fig. 10. Vertical component of the current in meters per hour, $5 \mathrm{~m}$ beneath the sea surface. Dark and light areas, respectively, indicate downwelling and upwelling movements.

alongshore coastal current a few kilometers wide. Once again, the external forcings, and here especially the ambient circulation, would have to be accurately represented in order to ruly validate the model. Indeed, for mild wind conditions, the continental shelf circulation is generally characterized by a westward alongshore current, often designated as the 'Liguro-Provençal' current (Millot, 1990). According to Millot (1990), it seems that this coastal current may be reasonably estimated at $5-10 \mathrm{~cm} / \mathrm{s}$. We thus tested the sensitivity of the simulation described in Section 3 to an ambient westward current of the order of $5 \mathrm{~cm} / \mathrm{s}$. Our results come close to O'Donnell's description of the effects of ambient current on the shape of the plume (O'Donnell, 1990): the general plume shape is slightly modified by the crossflow, which however enhances the downstream spreading while tending to restrict the upstream and off shore extension of the bulge. It may therefore be assumed that the eastward extension towards the Gulf of Fos can be influenced by the coastal circulation. An accurate representation of the continental shelf circulation associated with the 'Liguro-
Provençal' current should enable future studies to test this hypothesis.

\section{Sensitivity to the vertical coordinate system}

The double-sigma coordinate system was introduced into our model since, as it offers the advantage of preserving the horizontal resolution of the surface layer despite the variable bottom topography (unlike the conventional sigma system), it was felt that the vertical structure of the plume would be better represented in the open sea, which would clearly lead to a better representation of the resultant pressure gradients and circulation. We thus assessed the sensitivity of the model to the vertical coordinate system by performing a simulation analogous to the reference simulation, except that the restriction on the thickness of the upper layer was removed, thus implying that the vertical grid would be similar to a conventional sigma grid.

The general shape of the plume as calculated by the conventional sigma version is not very different 
from the one calculated by the reference simulation. The seaward extension of the anticyclonic bulge is slightly shorter than in the reference simulation, but the westward alongshore extension of the plume is longer. A truly significant difference finally appears in the horizontal salinity gradients: the reference simulation results in a much more pronounced salinity front, in particular in the bulge, while the simple sigma simulation results in a gradual dilution of the plume as it gets farther from the river mouth. One consequence of the salinity front dilution is a decrease of about $30 \%$ in the maxima of the velocities calculated inside the bulge.

A likely explanation of the salinity front dilution in the case of the simple sigma simulation is that, as the plume flows seaward, the model distributes the freshwater over a larger and larger vertical mesh, and the value of $S$ at the surface consequently increases simply by considering the salt conservation criterion. This flaw is accompanied by an excessive thickening of the plume.

\section{Discussion and conclusion}

The Rhône River plume was studied by means of a 3-D model with a $1-\mathrm{km}$ horizontal mesh, which made it possible to solve for the internal radius of deformation, of the order of $4 \mathrm{~km}$ inside the plume, and to represent the complex topographical characteristics, principally the canyon extending in front of the river mouth and the Gulf of Fos, which exercise a considerable influence on the plume shape. Similarly, a double-sigma vertical coordinate was used, as it enabled a finer representation of the effects of the bottom topography all the while conserving the vertical resolution required for the accurate representation of the surface plume. This choice proved to be more suitable for the representation of the frontal areas than a conventional sigma coordinate, which artificially increases the plume dilution and reduces the currents associated with it. Since the purpose of this study was to understand the mechanisms controlling the formation of the plume, a depth-averaged current vorticity analysis was performed. Mean flood conditions were chosen since, even though they represent a period of only about one month per year, they are accompanied by the discharge of a large portion of the solid continental matter transported by the river over the scale of one year. An understanding of the plume dynamics is fundamental to predicting the fate of this matter on the continental shelf. When compared to the plumes simulated in idealized conditions (Chao and Boicourt, 1986; Chao, 1988; O'Donnell, 1990), the Rhône River plume has certain unique characteristics resulting from the particularities of the coastline and bottom topography, and the high speed of the current as it leaves the river. The plume calculated by our model may be considered as supercritical-diffusive according to the classification scheme defined by Chao (1988). There may be several reasons for this: the high current speeds inside the plume, resulting on the one hand from the considerable buoyancy created by the discharge of the freshwater onto the continental shelf, which occurs over the entire water column (due to the absence of estuarine circulation), and on the other hand from the high speed of the current in the river. The diffusive characteristic may be attributed to the vertical movements, brought about by the bottom topography, which are the cause of the gradual dilution of the plume.

As mentioned in Section 3, the Rhône River plume does not agree with the general rule derived from Garvine's classification by Kelvin number, since both $\mathrm{Ke}$ and $\mathrm{Fr}$ are higher than 1. A comparison with the case of the Rhine seemed worthwhile since the Rhine shares certain characteristics with the Rhône system, such as the mean freshwater discharge (about $2000 \mathrm{~m}^{3} / \mathrm{s}$ ) and the Kelvin number (about 3). Moreover, recent studies on the Rhine River plume, conducted with a 3-D model similar to the one used here (Ruddick et al., 1994, 1995) provide substantial material for comparison with our results. While there is some disagreement between Garvine's classification (Table 1) and Ruddick's (1994) estimate of the Froude number (Ruddick's estimate is indeed about 0.9), it seems that the Rhine River plume may reasonably be considered to be subcritical. The case of the Rhine differs from that of the Rhône when it comes to the plume shape as well. Indeed, Ruddick's experiments demonstrate that the tidal currents and the relatively shallow bathymerry induce considerable turbulent mixing which enhances the dilution of the Rhine River plume. On the other hand, the Rhône River plume is characteristic 
of a weak ambient current situation (for no wind conditions), because of the lack of tidal currents and the low velocity of large-scale circulation on the shelf (Millot, 1990) when compared to the plume velocity. This, added to the steep bathymetry which diminishes the effects of bottom friction, prevents the generation of turbulent mixing and encourages the relatively long extension of a thin surface plume with strong currents $(\mathrm{Fr}>1)$.

One remarkable characteristic of the Rhône River plume is the size of the anticyclonic eddy, which flows from the river mouth to the Gulf of Fos, extending considerably eastwards and then seawards. The mechanisms governing this progression seem tightly linked to the topography on the one hand, and to the momentum advection on the other hand. Upon exiting the river mouth, the plume acquires cyclonic vorticity which enables it to penetrate the Gulf of Fos. Once the components of this vorticity were analyzed, it was possible to demonstrate that this effect is caused by the stretching term, generated by the bottom slope, and by the nonlinear terms. The advection plays an important role here, since it is the dominant term in the vorticity balance. A simulation in which the advection is not taken into account shows that due to the shallow depth, the friction becomes the preponderant term, intensifying even further the cyclonic turning of the circulation, which has itself become highly baroropic against the westem coast of the Gulf of Fos, thus encouraging the penetration of the river water up to the far end of the Gulf. Inside the Gulf of Fos, the plume begins its anticyclonic rotation, which is one of the main characteristics of the river water flow in front of the river mouth. The JEBAR term is the cause of this negative vorticity, due to the orthogonality of the isopycnals and of the bathymetrical contours. Here as well, the significant role of the nonlinear terms needs to be emphasized, as they generate the cyclonic vorticity whose effect is then embodied by a relatively low net anticyclonic vorticity, and thus by a bulge with a long seaward extension.

We decided to test the sensitivity of the model to advection, since it was felt that the depth-averaged current was insufficient for analyzing the effect of the nonlinear terms on the net vorticity, due to the vertical shear. The analysis of the sensitivity to advection demonstrated that this term is in fact deter- minant in the size of the bulge since, unlike the situation near the river mouth, the friction here is not able to compensate for the absence of advection, which greatly increases the anticyclonic vorticity by reinforcing the preponderance of the JEBAR term. The result of a negligible advection is thus a significant decrease in the size of the anticyclonic bulge. Simulations which have not been included in this article have demonstrated that in this part of the plume, the advection is only negligible for low values of river discharge $\left(<1000 \mathrm{~m}^{3} / \mathrm{s}\right)$, thus indicating that the plume shape as shown in Fig. 2 is representative of the majority of situations. The pertinence of the numerical experiment without wind is moreover confirmed by a satellite observation which clearly highlights the anticyclonic bulge and the advance of the plume towards the Gulf of Fos.

An interesting fact which should also be noted, and which is not represented in idealized situations, is the rise in the bathymetry encountered by the plume in the eastem part of the Gulf of Fos. The JEBAR term then generates a cyclonic vorticity which pushes the plume against the coast until it reaches Cap Couronne, and thus participates in the eastward advancement of the freshwaters. The anticyclonic bulge is the center of the rising movements which dilute the river waters considerably. The diffusive effects result in a much wider coastal current than the value predicted in the inviscid case, since it attains about $10 \mathrm{~km}$, i.e. more than twice the value of the intermal Rossby radius. The momentum advection plays a particularly significant role here in keeping the nose of the plume pushed against the coast and thus reducing the loss of mass by lateral detrainment. When the momentum advection is omitted, it may effectively be observed that the salinity front which bounds the plume is more diluted than in the reference simulation. It should be noted that unlike the behavior previously observed in the bulge, the effect of the advection is always strong on the nose of the plume, regardless of the discharge, due to the horizontal gradients which characterize the nose and the unsteadiness linked to the advance of the front.

The study of sensitivity of the plume to a northwestem wind resulted in a plume shape which closely resembles the satellite observation statistics of Demarcq and Wald (1984). For a discharge of 5000 $\mathrm{m}^{3} / \mathrm{s}$ lasting $48 \mathrm{~h}$, it seems that the plume detaches 
itself from the coast when the order of magnitude of the wind stress is at least $0.03 \mathrm{~N} / \mathrm{m}^{2}$. This value is relatively comparable to the estimate calculated using dimensional analysis by Garvine (1995). The interface between the plume and the subjacent seawater is characterized by the propagation of internal gravity waves.

\section{Acknowledgements}

This study was supported by the Programme National d'Océanologie Côtière (we thank H. Massé who coordinated the program in the Gulf of Lions) and by the European Community under contract MAS3-CT96-0049 (METRO-MED project). Didier Pont is thanked for helpful discussions on the Rhône River Mouth. We are also grateful to S. Prieur, Y. Meyerfeld and A. Urielli.

\section{Appendix A}

The calculation of the vorticity balance Eq. (17) on the model grid is performed using the depth-integrated momentum equations employed by the model in order to calculate the external mode solution (Blumberg and Mellor, 1987). These equations are expressed as:

$$
\begin{aligned}
& \frac{\partial H \overline{u_{i}}}{\partial t}+\frac{\partial}{\partial x_{k=1,2}} \int_{-h}^{\eta} u_{k} u_{i} \mathrm{~d} x_{3}-\varepsilon_{i j 3} H \overline{f u_{j}} \\
& =\frac{g}{\rho_{0}} \int_{-h}^{\eta} \frac{\partial}{\partial x_{j}}\left(\int_{x_{3}}^{\eta} \rho \mathrm{d} x_{3}^{*}\right) \mathrm{d} x_{3}+\frac{\tau_{\mathrm{s}, j}-\tau_{\mathrm{b}, j}}{\rho_{0}} \\
& \quad+A \Delta H \overline{u_{i}}
\end{aligned}
$$

The time splitting technique is based on the decomposition of the various terms in Eq. (A1) into a barotropic component and a depth-dependent component (notably for the advection and the pressure gradient). This last point, which does not play a part in the discussion below, will not be developed here. The reader is referred to Blumberg and Mellor (1987) for more details. After division by $H$ and crossed horizontal derivatives, Eq. (A1) becomes:

$$
\begin{aligned}
\varepsilon_{i, j, 3} & \frac{\partial}{\partial x_{i}}\left(\frac{1}{H} \frac{\partial H \overline{u_{j}}}{\partial t}\right) \\
= & -f \frac{\overline{\partial u_{k}}}{\partial x_{k=1,2}}-\varepsilon_{i, j, 3} \frac{\partial}{\partial x_{i}}\left[\frac{1}{H} \frac{\partial}{\partial x_{k=1,2}} \int_{-h}^{\eta} u_{k} u_{j} \mathrm{~d} x_{3}\right. \\
& +\frac{g}{\rho_{0} H} \int_{-h}^{\eta} \frac{\partial}{\partial x_{j}}\left(\int_{x_{3}}^{\eta} \rho \mathrm{d} x_{3}^{*}\right) \mathrm{d} x_{3}-\frac{\tau_{\mathrm{s}, j}-\tau_{\mathrm{b}, j}}{\rho_{0} H} \\
& \left.-\frac{A \Delta_{h} H \overline{u_{j}}}{H}\right]
\end{aligned}
$$

It may be observed that the pressure, Coriolis and advection terms are equivalent to the JEBAR, stretching and nonlinear terms of Eq. (17), meaning that it is easy to determine the latter in a manner consistent with the model calculations. On the other hand, this is not the case for the terms of horizontal diffusion and change in vorticity over time. It may also be observed that the term representing change in surface elevation over time:

$$
\varepsilon_{i j 3} \frac{\partial}{\partial x_{i}}\left(\frac{\overline{u_{j}}}{H} \frac{\partial \eta}{\partial t}\right)
$$

is missing in Eq. (A2). In fact, it is simple to make this latter term appear, as well as the term representing change in vorticity over time, by considering that:

$\varepsilon_{i, j, 3}\left[\frac{\partial}{\partial x_{i}}\left(\frac{1}{H} \frac{\partial H \overline{u_{j}}}{\partial t}\right)\right]-\frac{\partial \xi}{\partial t}=\varepsilon_{i, j, 3}\left[\frac{\partial}{\partial x_{i}}\left(\frac{\overline{u_{j}}}{H} \frac{\partial \eta}{\partial t}\right)\right]$

Finally, identical results may be obtained between the right- and left-hand sides of Eq. (17) if Eq. (A3) is chosen as the finite-difference equivalent of the change in surface elevation over time, and if the horizontal diffusion term is calculated as in Eq. (Al).

\section{References}

Arakawa, A., Suarez, M.J., 1983. Vertical differencing of the primitive equations in sigma coordinates. Mon. Weather Rev. 111, 34-45.

Asselin, R., 1972. Frequency filters for time integrations. Mon. Weather Rev. 100, 487-490. 
Blumberg, A.F., Mellor, G.L., 1987. A description of a three dimensional coastal circulation model. In: Heaps, N.S. (Ed.), Three-Dimensional Coastal Ocean Models. Coastal and Estuarine Sciences 4, American Geophysical Union, Washington, D.C., pp. $1-16$.

Chao, S.-Y., 1988. River forced estuarine plumes. J. Phys. Oceanogr. 18, 2137-2149.

Chao, S.-Y., Boicourt, W.C., 1986. Onset of estuarine plumes. J. Phys. Oceanogr. 16, 2137-2149.

CTGREF, 1977. Etude écologique du Rhône. Site de Bugey, Chavanay, Tricastin. Rapport à E.D.F., 102 pp.

Deleersnijder, E., Beckers, J.M., 1992. On the use of the sigma coordinate system in the regions of large bathymetric variations. J. Mar. Syst. 3, 381-390.

Demarcq, H., Wald, L., 1984. La dynamique superficielle du panache du Rhône d'après l'imagerie infrarouge satellitaire. Oceanol. Acta 7 (2), 159-162.

Garvine, R.W., 1987. Estuarine plumes and fronts in shelf waters: A layer model. J. Phys. Oceanogr. 17, 1877-1896.

Garvine, R.W., 1995. A dynamical system for classifying buoyant coastal discharges. Cont. Shelf Res. 15, 1585-1596.

Gaspar, P., Gregoris, Y., Lefevre, J.M., 1990. A simple eddy kinetic energy model for simulations of the oceanic vertical mixing: tests at station Papa and long-term upper ocean study site. J. Geophys. Res. 95, 179-193.

Johns, B., Marsaleix, P., Estournel, C., Véhil, R., 1992. On the wind-driven coastal upwelling in the Gulf of Lions. J. Mar. Syst. 3, 309-320.

Kourafalou, V.H., Oey, L.-Y., Wang, J.D., Lee, T.N., 1996a. The fate of river discharge on the continental shelf, 1. Modeling the river plume and the inner shelf coastal current. J. Geophys. Res. 101, 3415-3434.

Kourafalou, V.H., Lee, T.N., Oey, L.-Y., Wang, J.D., 1996b. The fate of river discharge on the continental shelf, 2. Transport of coastal low-salinity waters under realistic wind and tidal forcing. J. Geophys. Res. 101, 3435-3455.

Lentz, S.J., Limeburner, R., 1995. The Amazon river plume during AMASSEDS: Spatial characteristics and salinity variability. J. Geophys. Res. 100, 2355-2375.

Mertz, G., Wright, D.G., 1992. Interpretations of the JEBAR term. J. Phys. Oceanogr. 22, 301-305.

Millot, C., 1990. The Gulf of Lions' hydrodynamics. Cont. Shelf Res. 10, 885-894.

O'Donnell, J., 1990. The formation and fate of a river plume: a numerical model. J. Phys. Oceanogr. 20, 551-569.

Orlanski, I., 1976. A simple boundary condition for unbounded hyperbolic flows. J. Comput. Phys. 21, 255-261.

Pinazo, C., Marsaleix, P., Millet, B., Estournel, C., Véhil, R., 1996. Spatial and temporal variability of phytoplankton biomass in upwelling areas of the northwestern Mediterranean: a coupled physical and biogeochemical modelling approach. J. Mar. Syst. 7, 161-191.

Ruddick, K.G., Deleersnijder, E., De Mulder, T., Luyten, P.J., 1994. A model study of the Rhine discharge front and downwelling circulation. Tellus 46A, 149-159.

Ruddick, K.G., Deleersnijder, E., Luyten, P.J., Ozer, J., 1995. Haline stratification in the Rhine-Meuse freshwater plume: a three-dimensional model sensitivity analysis. Cont. Shelf Res. 15, 1597-1630.

Stern, M.E., Whitehead, J.A., Hua, B.L., 1982. The intrusion of a density current along the coast of a rotating fluid. J. Fluid Mech. 123, 237-265.

Tsimplis, M.N., Proctor, R., Flather, R.A., 1995. A two-dimensional tidal model for the Mediterranean Sea. J. Geophys. Res. 100, 223-239.

Weaver, A.J., Hsieh, W.W., 1987. The influence of buoyancy flux from estuaries on continental shelf circulation. J. Phys. Oceanogr. 17, 2127-2140.

Wheless, G.H., Klinck, J.M., 1995. The evolution of density-driven circulation over sloping bottom topography. J. Phys. Oceanogr. $25,888-901$.

Wu, J., 1980. Wind-stress coefficients over sea surface near neutral conditions-a revisit. J. Phys. Oceanogr. 10, 727-740. 